\title{
Effect of mind-maps among medical students
}

\author{
Amrita R.S., Krishna Prasad, M.S., Rishmitha, R., Megan, F.
}

\begin{abstract}
Mind-maps are like Da Vinci's notes which are multisensory tools that use visual-spatial orientation to integrate information and consequently help students to organize and retain information. Mind map allows a user to grasp and depict the essence of a particular topic on a single page. This learning style is a combination of graphics, symbols, text and pictures in a given context (Buzan \& Buzan, 2010; Gelb, 1998).
\end{abstract}

Mind maps provide a complete picture about the subject with links that enable a student to expand on the current information. Each branch arising from the main concept written as the central image can create a new Mind Map. Mind map is a diagram used to represent words, ideas, tasks or other items linked to and arranged around a central key or idea.

Mind-maps serve as 'memory hooks' to which the rest of the information will be attached. "Relationship between mind-map learning strategy and critical thinking in medical students" a study conducted at Seton Hall University; that mind-map as learning tool was used to evaluate the 'recall component' of the Domain - knowledge based information. 131 medical students of first year were divided into two groups who were assessed with a quiz. Short term memory was assessed, however long-term memory was not assessed (D'Antoni et al., 2010).

Purpose of this study was to analyze the effect of the use of mind maps in long term retention. The study is a mixed method. It consists of both qualitative and quantitative analysis.

Department of Microbiology, SIMS \& RC, Mukka, Mangaluru.

Correspondence address:

Dr.Amrita.R.Shriyan,

Convenor MEU \& Associate Professor,

Department of Microbiology, SIMS \& RC

Email:dramrita@ymail.com
After approval from Institutional Ethics Committee, a total of 80 students from $2^{\text {nd }} \mathrm{yr}$. M.B.B.S, SIMS \& RC, Mukka were randomly selected for a comparative study on learning technique. A before and after study design was used to analyze the performance of students using mind-maps in microbiology subject. Forty randomly selected students (Group A) were taught; "How to create Mind-maps" as Selfdirected learning (SDL) tool.

\section{Qualitative analysis:}

A test was given on a topic after a students were asked to read a new topic by mind map technique. A relatively new topic was selected so that the existing knowledge in the selected study material will not interfere with the results. Both the study groups were evaluated on their performance by pre-validated pre-test and a post-test. A week later the same topic was taught and a test was given to both the groups on the same topic after 3 weeks in the sessional exam.

\section{Qualitative analysis:}

There have been limited number of studies addressing the issues of understanding the teaching and learning process in medical education which indirectly influences the competence among medical graduates in this region. Perception of the students was analyzed based on the feedback forms.

\section{Results:}

Group A \& B students had an average score of 5.17 and 3.6 out of 10 respectively. Pass percentage of $>50 \%$ was $32 / 40$ in group A \& $20 / 40$ in group B. Forty-five students felt the need to change their learning techniques. Comparison of scores showed significant $p$ value .000538 (t-value 3.37795). Group A students were more confident to face exams since they could recollect the vast topics with rapid revision using mind maps. They were better at organizing their answers compared to other group who read by other methods like reading, group discussions and note making. 


\section{Discussion:}

Brain is divided into two hemispheres, the leftbrain is said to be the logical, analytical side and the right-brain the artistic, creative side. Mind map will stimulate both sides of the brain and help an individual to grasp, understand and retain an information better (Toi, 2009). Thus, we need to look beyond the traditional teaching and learning process and focus on the learning pattern or learning process in our students. By route learning has been the prime focus of learning method, which has resulted in loss of creativity and imagination, leaving no scope for analysis, interpretation and to improve further on the existing knowledge.

Mind-Mapping can thus achieve a substantially higher gain in conceptual understanding and practical reasoning than students using conventional study techniques. Our results were quite similar to the findings observed a study (Farrand et al., 2002) in the subject of anatomy. A 'self-selected study technique' was adopted by one group and 'mind map' by another group. It was observed that Recall of factual material improved for those in the mind map group after a week.

\section{Conclusion:}

Mind-maps help students to organize and retain information since it involves radiant thinking, the natural way in which a human brain function.

\section{References:}

Buzan, T. \& Buzan, B. (2010) Mind Map Book, London: Rajpal \& Sons.

D'Antoni, A.V., Zipp, G.P., Olson, V.G. \& Cahill, T.F. (2010) Does the mind map learning strategy facilitate information retrieval and critical thinking in medical students? BMC Medical Education, 10, 1, pp. 61.

Farrand, P., Hussain, F. \& Hennessy, E. (2002) "Efficacy of mind-map study technique", Medical Education, 36, 5, pp. 426-431.

Gelb, M.J. (2009) How to think like Leonardo da Vinci: Seven steps to genius every day, New York: Dell.

Toi, H (2009), Research on how Mind Map improves Memory, In International Conference on Thinking, Kuala Lumpur, Malaysia. 